\title{
Running FASTER: Changing Running Technique to Reduce Stress Injuries
}

\author{
Donald F. Kessler, MEd, ATC \\ Naval Special Warfare Center, United States Navy
}

I have been a runner for 60 years. Starting as a miler as a freshman in high school, I went on to run track and cross country through college and have continued through the years, running road races, marathons, triathlons, and Masters Track. Needless to say, I have a great deal of running experience. I have also been an athletic trainer (AT) for 48 years. For 38 years I worked in the collegiate setting at the Naval Academy, Princeton, Rutgers, and San Diego State, mostly with the track teams. From both personal and professional experiences, I have seen just about every runningrelated injury. However, it was not until I started working as the AT for the Navy SEALs at Basic Underwater Demolition/SEAL Training (BUD/S) 10 years ago that I saw so many running-related stress fractures.

Stress-related injuries are extremely common with runners. While numerous risk factors for these injuries have been identified, the most common factor is related to training errors. ${ }^{1}$ To this end, there has been a push to eliminate the term "overuse injuries" and move toward "training error injuries." "As an AT, I have been very familiar with stress injuries with track, and more recently with all sports, especially in their off-season conditioning. Through my many years as an AT, I have come across numerous preventative and rehabilitative programs for reducing stress-related problems in runners. However, re-injury is still highly prevalent. ${ }^{3-7}$ It is apparent that the current standard for rehabilitating and preventing stressrelated injuries may not be adequate.

As I began my work with the students involved with BUD/S training, I found that the injured students were excellent athletes who had many things going against them in their running. As much as $60 \%$ of the long-term treatment provided during and after training was due to stress-related injuries. Unlike traditional running athletes, these students had to run in combat boots, wearing long pants, carrying back packs, inflatable boats, etc. They had to run 6 miles a day on concrete to the chow hall and 4-mile timed runs on soft beach sand. Many of the students had very little experience in fast-paced running and/or had no long-distance running background. It was clear to me that the majority of students who were developing stress-related injuries lacked the fundamental skills to make them effective runners. Most of the injured runners had backgrounds in sports such as swimming, water polo, ice

(C) 2020 Human Kinetics, Inc. Copyright claim excludes original work by authors, which was created within the scope of their employment with the U.S. Government.

Kessler serves as an athletic trainer within the United States Navy Basic Underwater Demolition/SEAL Training program at the Naval Special Warfare Center at Coronado Island in San Diego, CA. His clinical and research interests center on enhancing running performance and promoting safe strategies for returning to duty and sport in high-level military athletes. Address correspondence to Kesslerdon75@ yahoo.com. hockey, baseball, martial arts, and wrestling. These athletes did not have a history of running speed development or running efficiency.

The BUD/S training actually starts in Boot Camp for many weeks, followed by weeks in BUDS Prep, followed by more weeks of BUD/S Orientation. The First Phase consists of 3 more weeks of this type of training, before Hellweek begins. During Hellweek the students are on their feet $24 \mathrm{hr}$ a day, doing many activities from Sunday through Friday. Their training continues for 2 more weeks, before they have two more 6-week sessions for a Second and Third Phase. This translates to 62 weeks of continuous training in total. There is less focus on timed running in the later advanced training, but it is still an important part of their fitness. One thing was for certain-simply exposing the candidates to more running did not improve their running but, rather, often led to injury.

My task was to make the students who developed stressrelated injuries as efficient as possible when returning to full training. I knew that I would not be able to change how much they ran, where they ran, or what equipment they were wearing when they ran. However, based on their injuries, they were not running as efficiently as they could, due to their running background and the drawbacks aforementioned. My task as an AT was twofold: (1) they had to be able to pass the weekly 4-mile timed run and (2) not get re-injured. Knowing that the recurrence rate of running-related injuries is close to $50 \%$, I knew this was going to be a challenge.

At this time an interesting situation unfolded, Alberto Salazar and his Oregon Project team-some of the world's best runnerscame to the base to learn some mental conditioning skills. I talked to him about the problem of running efficiency in my students who had developed stress-related injuries. He told me that he had specific running efficiency techniques that he used to train his long-distance runners to be able to compete with the Kenyans (the best runners in the world at the time) in their races. He invited me to come up to his training facility in Oregon where he could show me what he does. I took up his invitation to watch his athletes train and learn more details of his techniques.

When I got there, I was expecting to sit back and watch the runners being coached. Instead, I sat in front of a computer and watched high-speed running profile videos, force plate videos, and treadmill runs by Galen Rupp and other high-level track athletes. I then moved on to watch running intervals on the track and listened to technique and form pointers that were given to the runners through the rest of their practices. That evening, thinking about Alberto's pointers, I went out on my own and tried to apply some of them to my own running. Amazingly, and almost instantaneously, I felt I was running with less effort and less pain on multiple consecutive days of running.

When I returned home, I took a couple of online courses by Jay Dicharry, in which he used treadmill running for the evaluations of 
runners to find functional deficiencies that may cause medical problems. I also used an app that was recommended by the Nike team physical therapist, Dave McHenry, to evaluate their runners. I was ready to evaluate my injured athletes, but first I thought it would be best to look at some research evidence to see if changing their style was even possible.

Much of my early search findings involved the research of Irene Davis ${ }^{8}$ and soon branched out to many others, concerning gait retraining, feasibility of improving running economy gait modification, managing bone stress injuries, and more. As I read through the literature on gait training, through the lens of Alberto's running techniques, I realized that there were several consistent factors to consider for improving running economy. Most striking to me though was that there was not an overall conceptual model to help clinicians, coaches, or runners link these factors together. There were also very few links that paired running efficiency and prevention of re-injury.

Following are the six elements for my conceptual map to improve running efficiency in my BUD/S students.

\section{Six Elements}

\section{Forward Lean}

The lean should be very minimal, ${ }^{9,10}$ from $5-7^{\circ}$, according to Alberto (see Figure 1). It is important that the lean is not greater or that it comes from bending at the waist. There are some who feel that the forward lean lets gravity assist you in running, but this has certainly been disputed. A better explanation seems to be that it causes a better posture, which allows one to activate the glutes more efficiently for power, rather than being so much quad

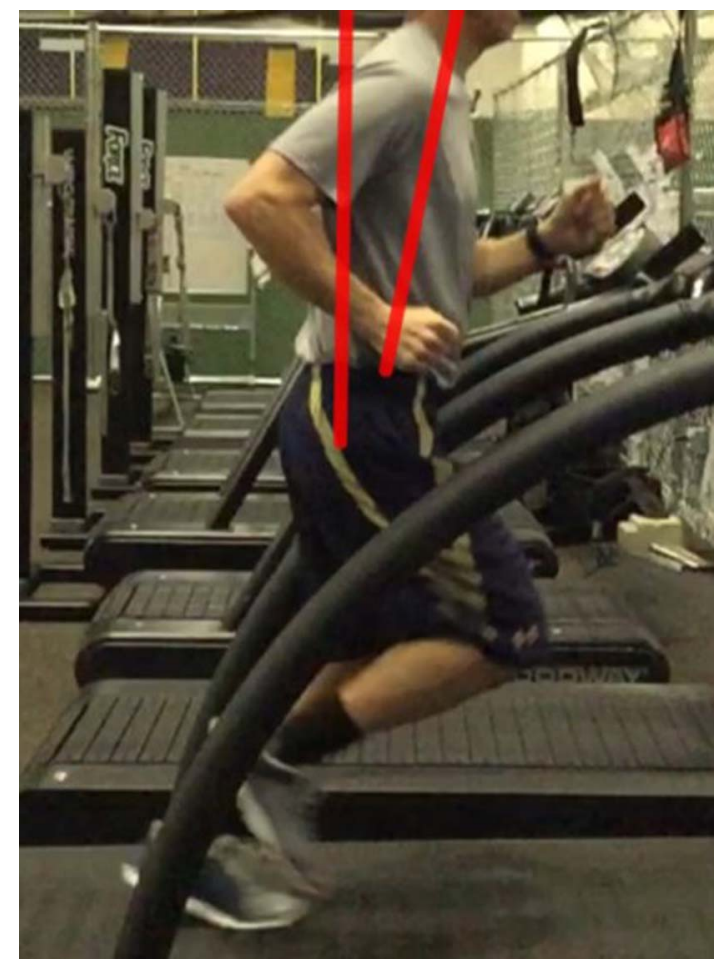

Figure 1 - Forward lean should be slightly increased from vertical. In this figure, the left line represents the vertical whereas the line represents the slight forward lean. Notice that the lean comes from the whole body rather than the trunk. dominated. Kinematics of the hip show that too much hip flexion may increase the risk of lower extremity injuries and affect running performance. ${ }^{11}$

\section{Arms}

Arm swing should run from the hips to the nipples (see Figure 2). When watching sprinters running, I have seen that their hands come up straight to their eyes and extend back behind the hips. With distance running this would be a tremendous waste of energy. The arms help with balance, counterbalance for the opposite leg, vertical lift, assist with forward motion, and decrease rotation. Upon observation I find that many distance runners seldom use their arms or use their arms in a manner that actually causes inefficiency and, possibly, medical problems.

If the arms are going side to side, or across the body, this causes rotation of the body. This uses excess energy and is not helping in forward propulsion, which causes extra stress to the lower extremities. This extra stress is added to bones, muscle, tendons, and other areas that also have to handle shock absorption or propulsion. These extra stressors are probably precursors to lower extremity stress problems.

The smooth motion of the shoulders, and the hands going hips to nips, keeps the rotational motions to a minimum. It also keeps excessive rise and fall of the center of gravity to a minimum.

\section{Stride Length: Close to the Center of Gravity}

Stride length is one of the most documented motions in the research. Most of the research points to many problems associated with overstriding. The evidence supports that overstriding may increase injury risk or make running inefficient and slower. There is evidence

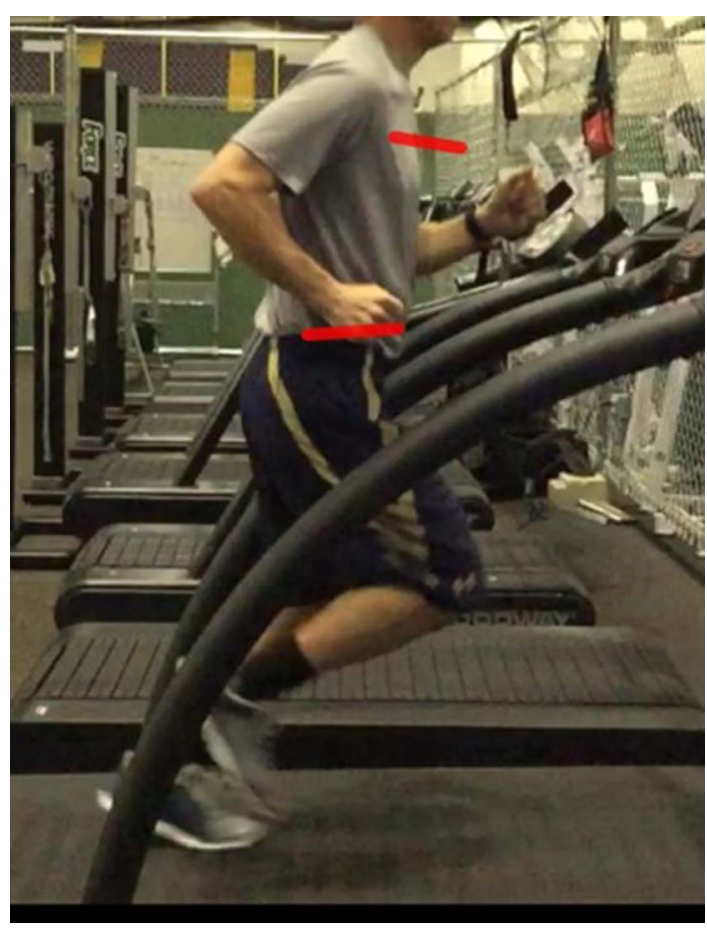

Figure 2 - Hips to nips. The hands should move alternately from the levels of the nipples to the hips. Notice the lines drawn to indicate the "hips to nips" motion. It is also important to not "roll" the shoulders, causing more body rotation. 
to support that, as stride length is decreased, the probability of stress fracture is decreased 3-6\%.12 Also, there is evidence to support that, as stride length is increased, more energy is absorbed. ${ }^{13}$

Overstriding often translates to a more extended knee on landing, resulting in increased braking forces slowing the runner down. By landing more closely to the center of mass, the knee is more flexed and the braking forces are diminished. An appropriate stride length can affect the time on the ground, foot placement, and revolutions per minute $(\mathrm{RPM})^{8,14}$ (see Figure 3 ).

\section{Trail Width-Step Width}

A rarely thought of and somewhat controversial point is foot placement and step width (i.e., how wide your feet should be from each other during ground contact). There is some evidence to support the idea that landing with a narrow step width (feet closer together) is more economical. ${ }^{15,16}$ However, it has also been proposed that greater foot and pelvic control are needed (especially within the frontal and transvers planes) with this style potentially contributing to iliotibial band and anterior tibialis pathologies as well as increased rotational forces on the tibia. ${ }^{17}$ While these are certainly valid points, it may be that a narrower trail/step width combined with overstriding results in increased stress to these areas.

The wider step width may appear to be more stable, but the runners tend to be slower, lumbering and rocking, moving the body weight from side to side. Alberto described this almost like a sailboat tacking, taking up more time and distance. He said to pay close attention to elite runners coming down a straightaway. Both their feet land on the same line. This allows all of the forces to push forward on the same vector. See Figure 4 for how I measure trail width.

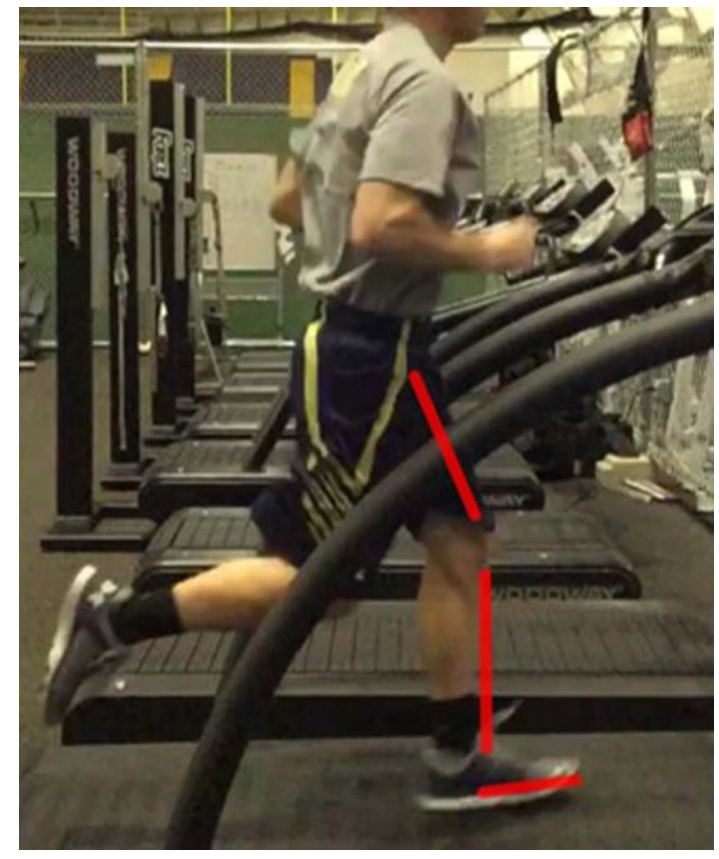

Figure 3 - Stride length. Foot strike should take place close to the center of mass - the further forward and away from the center of mass is indicative of overstriding. The lines indicate the relationship between foot strike and knee flexion angle as a result of striking close to the center of mass. Also, observe that the foot dorsiflexion angle should be more neutral, to be in an explosive position (see also Figure 5).

\section{Explode-Landing on the Midfoot, Pushing Off the Big Toe}

Much has been written and researched about foot strike, often driven by the popularity of barefoot running, minimal shoes, and even sandal running. As mentioned earlier, some of these points have shown to be interdependent on each other. There is evidence to support that a step rate increase of $10 \%$ will change runners to a more midfoot landing position. ${ }^{18}$ Decreased stride length increases step rate and decreases ground contact time, which makes forefoot or a midfoot strike pattern more economical compared to a rearfoot strike. ${ }^{19}$ Many of the "back of the pack" runners are rearfoot runners, whereas the elite and leaders are more midfoot runners.

By landing on midfoot, a runner is in a better position to reduce braking forces and transition to the explosive push-off quicker. ${ }^{20}$ Like an athlete doing plyometrics on to a box, the foot is in proper position to explode, although, in this case, forward instead of up. This is done by getting that last push-off the great toe, where $85 \%$ of force for propulsion is derived (see Figure 5). ${ }^{11}$

\section{RPM or Rate of Leg Turnover Cadence}

Alberto, and some other coaches, say that runners should maintain a cadence of 180 RPM. This translates to 90 strides per minute for each leg (ground contact to ground contact of the same leg). The exact number has been difficult to quantify in research, but there is

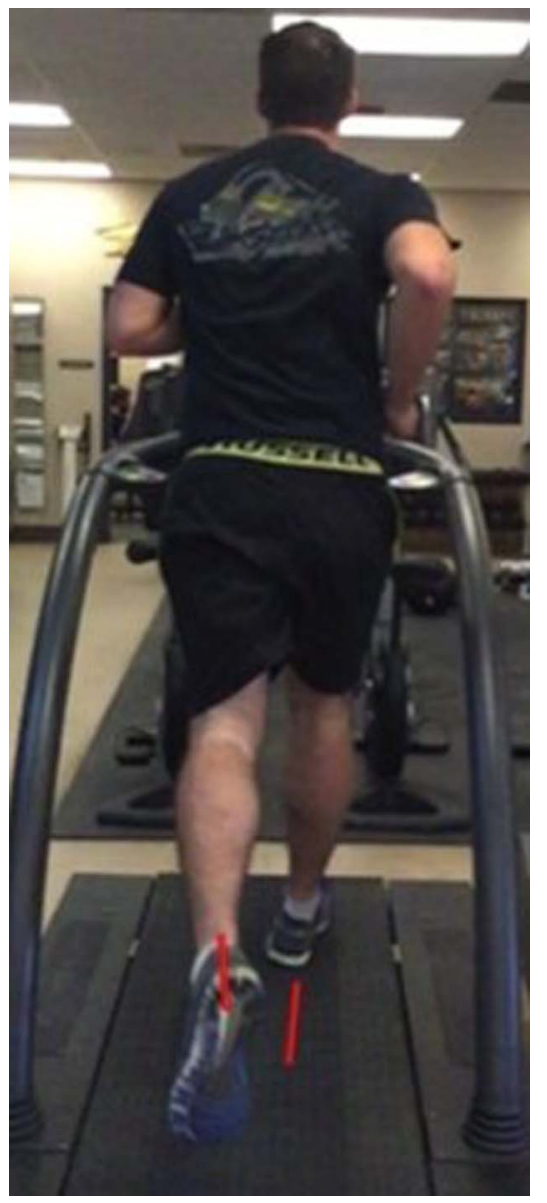

Figure 4 - Trail width. A narrow step width is more efficient than a wider one. In this figure, I use the lines as an easy way of identifying step/ trail width on a treadmill. 


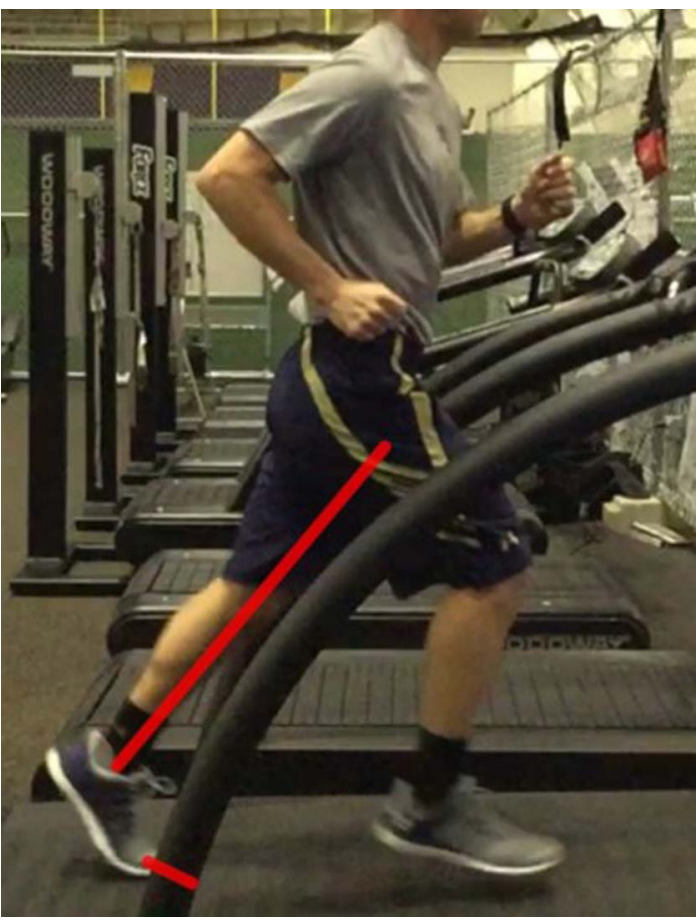

Figure 5 - Explosive push-off. The lines depict the use of the forefoot as a propulsive push-off. With the foot landing in a more neutral position, the position is easier to use kinetic energy in an explosive push-off.

evidence to support increased stride rate being beneficial. Recreational runners are mostly at 155 RPM, while high-level athletes are at 170 , even when jogging. An increase in the RPM of 5-15\% has been associated with less knee pathology, reduced impact loads, and less muscle damage. ${ }^{21,22}$ Other benefits of step increase include decrease of peak impact forces, decreased stride length, decreased hip adduction, and, as stated previously, more midfoot landing. For injured runners, cadence is a key to intervention. ${ }^{23-25}$

The multiple points that are interrelated here are that, as the RPM slows, runners tend to overstride, making them inefficient. As they overstride they land more on their heels, increase the braking forces, and spend more contact time on the ground. ${ }^{26-28}$ All of these slow the runner down more, gives them less explosion, and may lead to more stress-related injuries. Look at the leaders in a race compared to those behind them. The most striking characteristic is that you will probably see them maintaining a faster RPM.

\section{FASTER}

Taking all of these elements into consideration, I knew I had to come up with a handle-an easy guide - to help my students change and remember how to gain and maintain proper form. When I thought about my goal for the SEAL candidates who were returning to training and needed to have a running technique foundation, I realized it was right there in front of me. They needed to be FASTER.

- F: Forward lean

- A: Arms

- S: Stride length close to center of gravity

- T: Trail width-step width
- E: Explode_-landing on the midfoot, pushing off of the big toe

- R: RPM or rate of leg turnover cadence

The word FASTER should be easy for all runners to remember for training, racing, or running, especially when fatigued. If they can think of what each letter stands for, and keep good form, they should be efficient and not slow down as much as if their form were to diminish. I have found this to be a good psychological aid at the end of training runs and races, when fatigue sets in and "makes cowards of us all".

These are the elements that I use in teaching my injured students to build a better running foundation. Some students just need tweaks in their form, others need major overhauls. One thing I remind each of them is that there will be growing pains, real pains, throughout the learning process. The technique elements are not necessarily placed in a strict order, but more for the FASTER mnemonic-for context and easier memory. Most importantly, the elements are interdependent. Working on one or two elements at a time helps others to fall into place. I have enjoyed moments when I've seen my students actively working on the FASTER elements in their running and even laughed when I heard one student chanting "nips to hips" as his running mantra.

I have now used FASTER with my BUD/S students for 5 years. Real change has occurred. All of the runners through this program have passed their weekly 4-mile run test since returning to regular training. Some individuals have improved as much as 3-4 min over their previous best times. Of the 255 students who have been in the program with stress fractures, only seven have had repeat stress injuries. In three cases, the individuals admitted that they added extra mileage, on top of the prescribed training, or started running on their own before the release to do so. The command has been very happy with the results and even had me instruct uninjured run failures. All of these students have passed their run tests, too, and did not get injured. It can be done. They can become FASTER.

Medical personnel should examine the running gait of their patients as they return them to full functional ability. I highly recommend using the FASTER elements to teach better form and instill a better running foundation. A pitcher who has faulty throwing mechanics will probably be re-injured even if they have developed full strength and flexibility. Should it be any different for a runner who is returning to their old form? It might not be true that everyone will fit into the exact same form, but the FASTER elements can help anyone. My results with the vast number of BUD/S students indicate for me that it is reasonable, feasible, and possible to change running form and get good, longlasting results in terms of re-injury and being FASTER. I hope you find the same results.

\section{Disclaimer}

The views expressed in this Clinical Commentary are solely the author's and do not represent the views of the United States Department of Defense, the Department of the Navy, The Special Operations Command, or the Naval Special Warfare command.

\section{References}

1. Nielsen RO, Buist I, Sorensen H, Lind M, Rasmussen S. Training errors and running related injuries: a systematic review. Int J Sports Phys Ther. 2012;7(1):58-75. PubMed ID: 22389869

2. Drew MK, Purdam C. Time to bin the term 'overuse' injury: is 'training load error' a more accurate term? Br J Sports Med. 
2016;50(22):1423-1424. PubMed ID: 26843537 doi:10.1136/ bjsports-2015-095543

3. van der Worp MP, ten Haaf DS, van Cingel R, de Wijer A, Nijhuis-van der Sanden MW, Staal JB. Injuries in runners; a systematic review on risk factors and sex differences. PLoS One. 2015;10(2):e0114937. PubMed ID: 25706955 doi:10.1371/journal.pone.0114937

4. van Gent RN, Siem D, van Middelkoop M, van Os AG, BiermaZeinstra SM, Koes BW. Incidence and determinants of lower extremity running injuries in long distance runners: a systematic review. $\mathrm{Br} \mathrm{J}$ Sports Med. 2007;41(8):469-480; discussion 480. PubMed ID: 17473005 doi:10.1136/bjsm.2006.033548

5. Van Middelkoop M, Kolkman J, Van Ochten J, Bierma-Zeinstra SM, Koes B. Prevalence and incidence of lower extremity injuries in male marathon runners. Scand J Med Sci Sports. 2008;18(2):140-144. PubMed ID: 17555538 doi:10.1111/j.1600-0838.2007.00683.x

6. Saragiotto BT, Yamato TP, Hespanhol Junior LC, Rainbow MJ, Davis IS, Lopes AD. What are the main risk factors for runningrelated injuries? Sports Med. 2014;44(8):1153-1163. PubMed ID: 24809248 doi:10.1007/s40279-014-0194-6

7. van Poppel D, Scholten-Peeters GGM, van Middelkoop M, Koes BW, Verhagen AP. Risk models for lower extremity injuries among short- and long distance runners: A prospective cohort study. Musculoskelet Sci Pract. 2018;36:48-53. PubMed ID: 29729546 doi:10. 1016/j.msksp.2018.04.007

8. Crowell HP, Davis IS. Gait retraining to reduce lower extremity loading in runners. Clin Biomech (Bristol, Avon). 2011;26(1):78-83. doi:10.1016/j.clinbiomech.2010.09.003

9. Burfoot A. Does leaning forward help you run more efficiently by letting graving do some of the work? 2012. https://www.runners world.com/training/a20814323/does-leaning-forward-help-you-runmore-efficiently-by-letting-gravity-do-some-of-the-work/\#sidepanel. Accessed November 18, 2019.

10. Dos Santos AF, Nakagawa TH, Lessi GC, et al. Effects of three gait retraining techniques in runners with patellofemoral pain. Phys Ther Sport. 2019;36:92-100. PubMed ID: 30703643 doi:10.1016/j.ptsp. 2019.01.006

11. Rendos NK, Harrison BC, Dicharry JM, Sauer LD, Hart JM. Sagittal plane kinematics during the transition run in triathletes. J Sci Med Sport. 2013;16(3):259-265. PubMed ID: 22819075 doi:10.1016/j. jsams.2012.06.007

12. Edwards WB, Taylor D, Rudolphi TJ, Gillette JC, Derrick TR. Effects of stride length and running mileage on a probabilistic stress fracture model. Med Sci Sports Exerc. 2009;41(12):2177-2184. PubMed ID: 19915501 doi:10.1249/MSS.0b013e3181a984c4

13. Derrick TR, Hamill J, Caldwell GE. Energy absorption of impacts during running at various stride lengths. Med Sci Sports Exerc. 1998;30(1):128-135. PubMed ID: 9475654 doi:10.1097/ 00005768-199801000-00018

14. Napier C, MacLean CL, Maurer J, Taunton JE, Hunt MA. Kinetic risk factors of running-related injuries in female recreational runners. Scand J Med Sci Sports. 2018;28(10):2164-2172. PubMed ID: 29846979 doi:10.1111/sms.13228

15. Brindle RA, Milner CE, Zhang S, Fitzhugh EC. Changing step width alters lower extremity biomechanics during running. Gait Posture.
2014;39(1):124-128. PubMed ID: 23831430 doi:10.1016/j.gaitpost. 2013.06.010

16. Meardon SA, Derrick TR. Effect of step width manipulation on tibial stress during running. J Biomech. 2014;47(11):2738-2744. PubMed ID: 24935171 doi:10.1016/j.jbiomech.2014.04.047

17. Boyer ER, Derrick TR. Select injury-related variables are affected by stride length and foot strike style during running. Am J Sports Med. 2015; 43(9):2310-2317. PubMed ID: 26243741 doi:10.1177/036354651 5592837

18. Thompson MA, Gutmann A, Seegmiller J, McGowan CP. The effect of stride length on the dynamics of barefoot and shod running. $J$ Biomech. 2014;47(11):2745-2750. PubMed ID: 24935172 doi:10. 1016/j.jbiomech.2014.04.043

19. Diebal AR, Gregory R, Alitz C, Gerber JP. Forefoot running improves pain and disability associated with chronic exertional compartment syndrome. Am J Sports Med. 2012;40(5):10601067. PubMed ID: 22427621 doi:10.1177/0363546512439182

20. Daoud AI, Geissler GJ, Wang F, Saretsky J, Daoud YA, Lieberman DE. Foot strike and injury rates in endurance runners: a retrospective study. Med Sci Sports Exerc. 2012;44(7):1325-1334. PubMed ID: 22217561 doi:10.1249/MSS.0b013e3182465115

21. Heiderscheit BC, Chumanov ES, Michalski MP, Wille CM, Ryan MB. Effects of step rate manipulation on joint mechanics during running. Med Sci Sports Exerc. 2011;43(2):296-302. PubMed ID: 20581720 doi:10.1249/MSS.0b013e3181ebedf4

22. Hobara H, Sato T, Sakaguchi M, Sato T, Nakazawa K. Step frequency and lower extremity loading during running. Int J Sports Med. 2012;33(4):310-313. PubMed ID: 22383130 doi:10.1055/s-00311291232

23. Clarke TE, Cooper LB, Hamill CL, Clark DE. The effect of varied stride rate upon shank deceleration in running. J Sports Sci. 1985;3(1):41-49. PubMed ID: 4094019 doi:10.1080/0264041 8508729731

24. Hafer JF, Brown AM, deMille P, Hillstrom HJ, Garber CE. The effect of a cadence retraining protocol on running biomechanics and efficiency: a pilot study. J Sports Sci. 2015;33(7): 724-731. PubMed ID: 25369525 doi:10.1080/02640414.2014. 962573

25. Mercer JA, Devita P, Derrick TR, Bates BT. Individual effects of stride length and frequency on shock attenuation during running. Med Sci Sports Exerc. 2003;35(2):307-313. PubMed ID: 12569221 doi:10.1249/01.MSS.0000048837.81430.E7

26. Adams D, Pozzi F, Willy RW, Carrol A, Zeni J. Altering cadence or vertical oscillation during running: effects on running related injury factors. Int J Sports Phys Ther. 2018;13(4):633-642. PubMed ID: 30140556 doi:10.26603/ijspt20180633

27. Neal BS, Barton CJ, Birn-Jeffrey A, Daley M, Morrissey D. The effects \& mechanisms of increasing running step rate: A feasibility study in a mixed-sex group of runners with patellofemoral pain. Phys Ther Sport. 2018;32:244-251. PubMed ID: 29879639 doi:10.1016/j. ptsp.2018.05.018

28. Souza RB. An evidence-based videotaped running biomechanics analysis. Phys Med Rehabil Clin N Am. 2016;27(1):217-236. PubMed ID: 26616185 doi:10.1016/j.pmr.2015.08.006 